\title{
Cigarette taxation in China: lessons from international experiences
}

Teh-wei Hu

\begin{abstract}
This paper draws upon the experiences of foreign countries in implementing tobacco taxation to provide lessons the Chinese government can use when considering the feasibility of raising additional taxes on cigarettes. Based on current international data and Chinese published data, this paper concludes that there is still leeway to raise existing taxes. The Chinese government should consider conducting some pilot experiments in tobacco tax increases, with some of the new revenues allocated for tobacco control programmes as well as for financing healthcare services among the poor.
\end{abstract}

(Tobacco Control 1997;6: 136-140)

Keywords: tobacco tax; China

\section{Introduction}

Cigarette smoking is harmful for health, causing premature death through smokingrelated illnesses such as lung cancer and cardiovascular disease. Smoking is also responsible for substantial healthcare costs and lost productivity due to illness and premature death.

China currently has a relatively high prevalence rate of cigarette smoking. More than 300 million individuals in China are smokers, and approximately $30 \%$ of the world's smokers live in China. ${ }^{1}$ Previous research has estimated that each ton of tobacco consumed results in approximately one death. ${ }^{2}$ It has been predicted that 50 million Chinese children alive today will die prematurely as a result of tobacco use. ${ }^{3}$

According to the 1992 national household expenditure survey, urban per capita expenditures in China on cigarettes (54.28 Chinese yuan (Y) (US \$9.05)) were higher than healthcare and medical expenditures (Y41.51 (\$6.92)) and alcohol and soft-drink expenditures (Y45.92 (\$7.65)). ${ }^{4}$ This survey also showed that on average, per capita annual cigarette consumption was 33.03 packs, ranging from 24.32 packs for the low-income group to 33.58 for the middle-income group and 45.09 for the highest-income group. ${ }^{4}$

Given the size of the smoking population in China, it is not surprising that China is the largest cigarette-producing country. ${ }^{4}$ It produced 32.85 million cases or 82.125 billion packs (one case consists of 2500 packs) of cigarettes and used 1.85 million hectares for tobacco production during 1992, which represents a $93 \%$ increase in production and a $25 \%$ increase in tobacco growing area since 1981. ? Per capita consumption of cigarettes reached a peak in 1990 of 1437.8 cigarettes, and then declined slightly to 1417.3 in 1991 and 1400.4 in 1992. From 1981 to 1992 , per capita consumption increased by $62.8 \%$.

In recent years, China has made major progress in tobacco control by banning all cigarette advertising, increasing import duties on cigarettes, and banning cigarette smoking in some public places. Still, China is a major world consumer of cigarettes. A recent study indicated that 895600 individuals died of smoking-related illnesses in $1989 . .^{5}$ Medical care expenditures due to smoking were estimated at Y6.9 (\$1.15) billion in 1989, while the value of lost productivity or premature death was about Y20.13 (\$3.35) billion that year. The value of these resources could be used for many other productive services in the society.

Government agencies and health policymakers around the world have used a variety of policy alternatives to control tobacco smoking. ${ }^{6}$ These policies include a ban on cigarette advertising, the prohibition of cigarette smoking in public places, antismoking media campaigns, the prohibition of $\bigcirc$ cigarettes sales to minors or in vending machines, health education in schools, and taxation on cigarette products. The objectives of some of those tobacco control instruments in reducing tobacco consumption are obvious, while others are less certain. It is universally recognised that taxation on the sale of cigarettes has been very effective in accomplishing its aims. Despite variations in cigarette taxes, it is generally agreed that a tobacco tax is a reliable source of government revenue, a convenient and effective method of collecting revenue, and, most importantly, a deterrent to cigarette consumption.

The government of China relies on revenue from the tobacco tax as a major financial resource. The question is whether sufficient opportunity exists for raising existing tax on cigarettes in China to control cigarette smoking, while still being financially beneficial to the government. The purpose of this paper is to draw upon the experiences of foreign countries in implementing tobacco taxation, to 
provide lessons the Chinese government can use when considering the feasibility of raising the tax on cigarettes.

\section{Rationales for cigarette taxation and international experiences}

A fundamental principle of economics indicates that increased cigarette prices will reduce cigarette consumption. The retail price of cigarettes consists of the prices of the raw materials, labour costs, and taxes. In general, cigarettes are taxed at various levels of government, encompassing federal, state, and local areas. The most common form of cigarette tax is based on units of quantity of sales (an excise tax) whereas some governments apply a cigarette tax based on a fixed percentage of the price (an ad valorem tax).

In China, cigarette taxes are collected by the central government at the level of the manufacturer, according to the number of cigarettes produced. Once these cigarettes leave the factory, no additional tax is added. Therefore, it is called a product tax. Because it is imposed according to quantity produced, it can also be considered an excise tax. All cigarette factories are owned and operated by the government. Thus, tax collection administration is very efficient.

Excise taxes are easier to collect and do not change over time, while an ad valorem tax changes as the price of cigarettes changes, and may add more administrative costs in collecting tax revenues. Regardless of the form of cigarette taxes, an excise tax is a component of the retail price, thus reducing cigarette consumption. The reduction of cigarette consumption could result from either a reduction in the number of cigarettes consumed by smokers, or a reduction in the number of smokers.

\section{RATIONALES FOR CIGARETTE TAXATION}

Two rationales are used to justify a tax on cigarettes. ${ }^{7}$ The first rationale is simply to consider the cigarette tax as an efficient instrument with low administrative costs for collecting revenue for government spending. In the case of the United States, an increase in the federal cigarette tax was used to finance the Civil War in 1864, and the Korean War in 1951. Thus, before 1960, taxes on cigarettes were enacted and raised to generate revenue rather than to discourage consumption. Similarly, in Finland, a major increase in cigarette price (a $60 \%$ increase in a seven-month period during 1975/ 76) was intended mainly to increase state revenue. $^{8}$

The second rationale for imposing a cigarette tax is to consider taxes as "user fees". It is argued that the tax covers the external costs of smoking and will discourage smokers from using cigarettes, thus leading to a reduction in tobacco-related healthcare costs by reducing the morbidity and mortality associated with cigarette smoking. This second rationale, with its anti-smoking objective for raising cigarette taxes, came into use after release of the US Surgeon General's 1964 report on smoking and health. Since 1980, countries such as Finland, Denmark, Egypt, Canada, Nepal, Iceland, Peru, Australia, and New Zealand have raised cigarettg taxes as a means to reduce cigarette consumption.

Given the rationale of raising cigarette tax to control tobacco use, many ç্য tries and states have used part of the revenue from such taxes to support anti-smoking actionities, such as health education, medical research on tobacco-related diseases, and a⿳⺈,i-smoking media campaigns-for example, Australia and New Zealand. In Victoria, Aus ralia, a 5\% tax was levied on the sale of tobage products in 1987 to finance health promotion. ${ }^{9}$ Other countries, such as Egypt and Nepal (personal communication with Minister of dealth, Yur Raj Sharma, 1995), have used the additional tax revenues for health-related actifyities, such as paying for low-income maternab and child

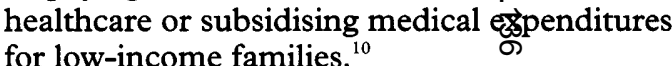
for low-income families. ${ }^{10}$

In November 1988 voters in California (USA) approved the California Tobacco Tax and Health Promotion Act (Props sition 99).

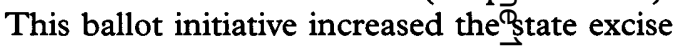
tax on cigarettes from 10 cents pefpack to 35 cents per pack, beginning in January 1989. It explicitly specified how the new fax revenue was to be used, including healt education programmes for the prevention an reduction of cigarette use, indigent healthcare, research, parks, recreation, environmental pogrammes, and other activities. ${ }^{11}$ Following a model programme funded by tobacco tax the state of Minnesota, ${ }^{12}$ Proposizinon 99 was the first state legislation in the United States that sought to deter cigarette c्छेnsumption both by increasing the state excise tax and waging an anti-smoking campaign

Studies show that six months gifter the tax increase in California, cigarette sales had declined by about one pack per adult, or $10.9 \%$. One year after the tax is crease, the decline per capita had remained a rate of three-quarters of a pack per adultoper month, or a $9.5 \%$ reduction throughout the next three years. $^{13}$

은

The cigarette tax increase led to in cigarette sales. Did the state's total revenues from cigarette sales decline? The Hswer is no. Based on the results of an estimated price elasticity of demand of -0.40 , it can boushown that a $10 \%$ increase in price reduces the quantity demanded by $4 \% .{ }^{14}$ Thus, the $e_{0}$ percentage increase in price is higher than the percentage decrease in quantity by six percerfitage points. In other words, the value of loss in sales is more than offset by the value of gains? due to the increased price. Therefore, tax repenues have increased. The actual California ste cigarette tax revenue increased $200 \%$ in $19 \%$, despite a $14 \%$ reduction in total cigamette sales. Cigarette sales continued to declire each year, while the revenue continued to be $\mathrm{Buch}$ higher than the pre-tax (1988) period. The state cigarette tax revenue in 1993 still was $170 \%$ higher than in 1988 .

This is a very important finding for policymakers in tobacco control and policymakers in tax revenue departments. As 
long as the price elasticity of the demand for cigarettes is less than -1 , the increase in taxes will result in a net gain in total tax revenues. The less elastic the demand, the less effective the tax will be in reducing cigarette consumption, but the more effective the tax will be in generating additional tax revenues. To plan for the desired level of reduction in cigarette consumption and the desired amount of increase in tax revenues, it is important to know the magnitude of the price elasticity of the demand for cigarettes.

California's anti-smoking legislation, Proposition 99, is a major success for the voters of California. Besides Minnesota and California, similar tax-funded initiatives in tobacco control have been implemented in the states of Massachusetts, ${ }^{15}$ Michigan, and Arizona.

CIGARETTE TAXES AND RETAIL PRICES AROUND THE WORLD

A cigarette tax is a major component of the retail price of cigarettes. It would be useful to know what proportion of the retail price is represented by cigarette taxes around the world. The Chinese government could use this information as a point of reference for their policy on cigarette taxes.

Most cigarette taxes are excise taxes, which means that the proportion of the retail price allocated to the tax may decline as the retail price increases. In other words, the real value of the excise tax will decline as inflation occurs over time. Some states in the United States and other foreign countries impose other sales tax fees on the cigarette product in addition to the excise tax. Therefore, it is more meaningful to compare the total taxes as a percentage of retail price. To make all prices comparable, it is useful to convert prices to US dollars per pack of cigarettes.

Based on data from December 1993 for 24 selected countries, the average retail price of cigarettes ranged from $\$ 0.63$ per pack in Spain to $\$ 4.55$ in Norway. ${ }^{16}$ The retail price of cigarettes in many Scandinavian countries (Norway, Denmark, Sweden, Finland), western European countries (United Kingdom and Eire), and Canada exceeded $\$ 3.00$ per pack. The United States price averaged $\$ 1.80$ per pack. Portugal, Argentina, Taiwan, Spain, and South Korea averaged less than $\$ 1.50$ per pack.

The amount of tax imposed on cigarettes in these 24 countries ranged from $\$ 0.42$ per pack in Spain to $\$ 3.48$ in Denmark, with an average of $\$ 1.66$ per pack. As a percentage of retail price, taxes in Denmark and the United Kingdom were the highest $-85 \%$ and $77 \%$, respectively. The percentage in 12 of the 24 countries exceeded $70 \% .{ }^{16}$ Those countries with cigarette prices less than $\$ 1.50$ per pack had high tax rates as well: $81 \%$ for Portugal, $70 \%$ for Argentina, $70 \%$ for Spain, and $60 \%$ for South Korea (with the exception of Taiwan, $47 \%)$.

According to official data reported by the General Taxation Bureau, Ministry of Finance, the cigarette product tax rates for China ranged from $35 \%$ to $60 \%$ in 1988 . However, these tax rates are calculated from the producer's point of view. According to the 1993 China statistical yearbook, sales revenues were 응 Y68.89 (\$11.48) billion in 1990 and Y76.75 (\$12.79) billion in $1991 .^{4}$ The government $\frac{O}{\partial}$ revenue from the cigarette tax was Y27 (\$4.5) $\stackrel{\overrightarrow{0}}{0}$ billion in 1990 and Y29 (\$4.8) billion in 1991. The reported retail price per pack was Y1.33 (US $\$ 0.22$ per pack) in 1992. Thus the effective retail tax rate was $39.2 \%$ in 1990 and $\frac{D}{\sigma}$ $37.78 \%$ in 1991 . In other words, out of every $\frac{\bar{\omega}}{\vec{D}}$ Y10 (\$1.66) spent by consumers on cigarettes, $\stackrel{\mathbb{Q}}{\Omega}$ consumers paid between Y3.8 (\$0.63) and Y3.9 (\$0.65) in taxes. Thus, in terms of tax $\vec{\circ}$ rates at the retail level, in China, rates are not as high as in many other countries.

\section{Government revenue and price elasticities}

The optimum amount of tax levied on cigarettes could be based on the economic burden of smoking to society, depending upon whether the purpose of the taxation is to control tobacco use, or, based on price elasticity, to maximise revenue. Cost estimates of the economic burden of cigarette smoking in the $\vec{\theta}$ United States range from $\$ 0.50$ per pack to $\$ 5.00$ per pack depending on the assumptions of the value of life and the extent of the negative impact of cigarette use-for example, smoking-related low birth weight-included in the calculation. ${ }^{17} 18$ No consensus exists in the $\triangle$ American research community as to which cost $\overrightarrow{\vec{\theta}}$ figure should be used as a basis for cigarette taxes. $^{19}$

On the other hand, if the purpose of a cigarette tax is to control tobacco smoking and at the same time maximise revenue, then the magnitude of price elasticity of demand for cigarettes will be an important reference point. For instance, in President Clinton's Health Security Act of 1993, the White House proposed a 75 cent per pack increase in the federal excise tax as one source of revenue to finance the health insurance programme. Based on 1992 taxes and cigarette smoking data, it was estimated that a 75 cent per pack increase in the federal cigarette excise tax would have prevented 900000 premature deaths. ${ }^{20}$

According to a 1990 World Bank report, revenue from tobacco products, alcoholic beverages, and gasoline accounted for approximately $27 \%$ of China's total product tax revenues in 1986. Cigarette tax revenue alone reached the peak percentage of $14.84 \%$ of total $\stackrel{\mathscr{D}}{+}$ government revenue in 1983, and then declined to $6.70 \%$ in 1986 . In recent years, cigarette taxes have contributed about $9.5 \%$ of total government revenues. For instance, in $\mathbb{D}$ 1992, the total government tax revenue was Y329.7 (\$54.9) billion; the cigarette tax 8 revenue that same year was Y31.0 (\$5.2) billion. Thus, cigarette taxes raised $9.4 \%$ of total government revenues. Clearly this tax represents a major source of government revenue.

To illustrate the possible revenue impact of an increased excise tax on cigarette sales, 1992 data on price and sales figures are used. 
According to the PRC (People's Republic of China) yearbook, the retail price per case of cigarettes was Y3320 (\$553), and 32.65 million cases were sold. ${ }^{4}$ A recent study estimated that the price elasticity of the demand for cigarettes in Sichuan province in China, ranges from -0.65 to -0.80 , which is somewhat higher (that is, more price sensitive) than in many other developed countries, but not as high as estimates from Papua New Guinea. ${ }^{4}{ }^{21}$ The Papua New Guinea estimates were for excise tax elasticity $(-0.50$ to -0.71$)$, and the price elasticity would be as high as -1.0 or $-1.42 .{ }^{6}$ In this illustration, we assume -0.65 (the lower end of the Sichuan estimate) to be the price elasticity for the Chinese population. ${ }^{22}$

Given this information, if the Chinese government cigarette industry imposed a $10 \%$ increase in price, from Y3320 (\$553) per case to Y3652 (\$608), a $6.5 \%$ reduction in sales would occur, from 32.65 million cases to 30.53 million cases. However, the total revenue would increase from Y108.41 (\$18.07) billion to Y111.5 (\$18.58) billion, a Y310 (\$51.67) billion increase, or an increase of $2.9 \%$. Thus, given the inelastic demand for cigarettes, the total revenue will increase when the price is increased. Assuming the effective tax rate in 1992 was $37.78 \%$, the effective tax rate would have to rise to $43.43 \%$ to achieve a $10 \%$ increase in price, an increase of $15 \%$ in the effective tax rate. Given these assumptions, total tax revenues would rise by $18.2 \%$, while total sales revenues would rise by $2.9 \%$.

\section{Options for additional cigarette taxes in China}

Given the negative health consequences of cigarette smoking, it is certainly justifiable to consider imposing additional tax on cigarettes. Furthermore, additional financial resources are needed to facilitate healthcare reform in China to expand the coverage of healthcare services for the poor, especially for the uninsured in the low-income urban and rural population. ${ }^{23}$ A number of countries, including the United States (California), Nepal, and Egypt, have been using tobacco tax revenues to pay for healthcare services or health insurance premiums. Finally, a serious need exists in China for a health promotion campaign and its financial support, which may include an anti-smoking media campaign or school health education programmes. A small portion of the additional cigarette tax revenues could be used to fund health promotion and disease prevention activities.

As noted above, China currently imposes a product tax on cigarettes. These taxes are incurred and paid directly by the producer; but leeway exists, however, for the consumer to pay an additional tax on cigarettes at the retail level in the form of a sales tax or an excise tax. Currently, cigarette taxes account for less than $40 \%$ of the retail price in China, not as high as many other countries in the world, where taxes comprise more than $60 \%$ of retail prices.

Several factors determine how much tax should be imposed. One major factor relates to the objective of reducing cigarette consumption. US data suggest that a third of the reduction in cigarette consumption following tax increases is the result of current sropokers quitting, and two-thirds is due to smokers reducing their individual cigarette consunption. The other factors relate to: (a) consumets' ability to bear the additional financial burfen; (b) the amount of revenue the government needs to achieve a given objective; (c) the nagnitude of the potential negative impact on cigarette industry; and (d) smuggling.

In California, before Propositîn 99 was implemented, the legislature had the intention of reducing tobacco consumption $\overrightarrow{\mid \vec{f}}$ California by $75 \%$ by the year 2000 . Canada, orecognising that its high tax rate caused majo $\vec{P}$ smuggling between Canada and the United Sitgtes, subsequently lowered its tax rate. In Egypt, the tax rate was increased from five to 10 piasters per pack to produce enough revenue to provide health insurance for schoo $E$ children. Therefore, the Ministry of Health, Ministry of Finance, and other interested parties in China need to collaborate in China's tax increase agenda.

Several concerns have beeno expressed relative to an increase in cigarette taxes. The first two have immediate impacts on increase in smuggling to avoid the ade्fitional tax burden, and the shifting from cigarette consumption to cigarette substitu震es (such as pipe or cigar smoking). These two responses will weaken the effect of an additional cigarette tax. Many countries, such as Cainada, have experienced the problem of gross-border smuggling. Smuggling in China $\mathrm{ds}$ already a major problem, especially between Hong Kong and China. The Chinese government has not been able to effectively control smuggling problem. The substition effect could be minimised if the tax covers not only cigarettes, but also other tobacco foducts.

One long-term negative consequence of an increased cigarette tax is the reduetion of the economic wellbeing of tobacco armers and workers in the tobacco industry, will face lost income and unemployment. $\Phi_{\mathrm{P}}$ this case, the government should develop follong-range gradual plan to convert tobseco farm production into other agriculturalfoproduction, and to convert tobacco faopories into non-tobacco factories by providin loans, the money for which can come from the cigarette tax. There will certainly be dispgoportionate losses to particular geographical ağeas. A similar policy debate is occurring in States. ${ }^{24-26}$ Brazil has encouraged tobacco farmers to transfer into other cash crop activities. Additional innovative policy a fernatives in this area should be considered. F.erhaps the World Bank can take further initigive, by not only refraining from lending for the purposes of tobacco production, but also by providing loans for converting tobacco production to production of alternative crops (H Barnum, unpublished paper, 1993). 


\section{Conclusions}

Many countries around the world have taken the initiative to control cigarette use because of its impact on public health and healthcare costs. China is in a unique position because its relatively high smoking prevalence provides a large tax base; therefore, the imposition of a cigarette tax increase will have a significant effect in generating revenue and reducing cigarette consumption. When combining tax revenue from both producers and consumers, the total revenue for the state will increase, not decrease.

The healthcare sector is currently facing limited financing sources, given the current state and local tax structure. Therefore, the option for raising additional revenues from a increased cigarette tax is a golden opportunity for China to finance healthcare reform and activities in health promotion and disease prevention.

This review of international experiences with cigarette taxation and the current status of Chinese cigarette consumption leads to the following recommendations.

- Tobacco tax policies in China should be linked to the objective of reducing tobacco use. Government policymakers should consider using tobacco tax as an intervention in accomplishing the goals of health promotion and disease promotion.

- Researchers have shown that tobacco taxation is an effective means of reducing cigarette consumption. Using a portion of cigarette tax revenue for anti-smoking activities would further achieve the goals of tobacco control.

China is a major country both in terms of the size of its population and the wide geographic differences in the production of tobacco and the manufacture of cigarettes. Raising cigarette taxes could be a major political and economic issue. One option for the central government is to carry out small-scale experiments in certain areas, like many other social and health insurance experiences being implemented in various local areas, to examine the potential impact of additional cigarette taxation on cigarette consumption, government revenue, possible allocation of additional tax revenue to health promotion and healthcare financing, and the Chinese cigarette manufacturing industry and tobacco farm sector.

An earlier version of this paper was prepared for the Human Development Department of the World Bank. The author is grateful for comments and suggestions provided by Professor Michael Grossman of the City University of New York, Dr William McGreevey of the World Bank, Professor Kenneth Warner of the University of Michigan, and three anonymous referees. Preparation of this paper was partially supported by the Pacific Rim Research Program, University of California. The interpretation and views expressed in the paper remain the responsibil- $\circ$ ity of the author and do not necessarily represent the views of the World Bank or the University of California.

The exchange rate for the yuan to the US dollar was $6: 1$ at the time of the figures quoted in this paper.

1 Chinese smokers pass the 300 million mark. Tobacco $\operatorname{Int} \frac{\overline{\bar{S}}}{\mathrm{O}}$ 1993;7:3-5.

2 Barnum $\mathrm{H}$. The economic burden of the global trade in tobacco. Tobacco Control 1994;3:358-61.

3 Novotny T, Peto R. Estimates of future adverse health $\frac{\bar{\omega}}{\sigma}$ effects of smoking in China. Public Health Rep 1988; 103:552-3.

4 State Statistic Bureau. 1993 Statistical Yearbook in China. \% China Statistical Publishing, 1993:220, table 6-6.

5 Jin SG, Lu BY, Yan DY, Fu ZY, Jiang Y, Li W. An evaluation $\overrightarrow{0}$ of smoking induced health costs in China (1988-1989). of smoking induced health costs

6 Warner K. Tobacco taxation as a health policy in the third $\vec{\omega}$ world. Am f Public Health 1990;80:529-30.

7 Zimring F, Nelson W. Cigarette taxes as cigarette policy. $\vec{\Omega}$ Tobacco Control 1995;4 Suppl 1:525-33.

8 Pekurinen $M$, Valtonen H. Price, policy, and consumption $N$ on tobacco: The Finnish experience. Soc Sci Med $\vec{\omega}$

Galbally $R$. Using the money generated by increased tobacco taxation. In: Slama $\mathrm{K}$, ed. Tobacco and health. Pro- $\mathrm{O}$ ceedings of the ninth world conference on tobacco and health ceedings of the ninth world conference on tobacco and health, New York: Plenum Press, 1995:139-42.

Reich M. School children's health insurance in Egypt. Harvard School of Public Health teaching case. Cambridge, Massachusetts: Harvard University, 1994.

11 Bal DG, Kizer KW, Felten PG, Mozar HN, Niemeyer D. $\overrightarrow{0}$ Reducing tobacco consumption in California. Development of a statewde anti-tobacco use campaign. $\mathfrak{F A M A}$. 1990;264:1570-4.

12 Harty KC. Animals and butts: Minnesota's media campaign against tobacco. Tobacco Control 1993;2:271-4.

13 Hu TW, Keeler T, Sung H, Barnett P. The impact of California anti-smoking legislation on cigarette sales, consumption, and prices. Tobacco Control 1995;4 Suppl 1:534-8.

14 Sung H, Hu T, Keeler T. Cigarette taxation and demand: an empirical model. Contemp Econ Policy 1994;7:91-100.

$15 \mathrm{Koh}$ HK. An analysis of the successful 1992 Massachusetts tobacco tax initiative. Tobacco Control 1996;5:220-5.

16 Lynch B, Bonnie R, eds. Growing up tobacco free. Washington, DC: Institute of Medicine, National Academy Press, 1994:184.

17 Manning W, Keeler E, Newhouse J, Sloss E, Wasserman J The taxes of sin: do smokers and drinkers pay their way? $¥ A M A$ 1989;261:1604-9.

18 Hay JW. The harm they do to others: a primer on the external costs of drug abuse. In: Krauss, MB, Lazear EP, eds Searching for alternatives: drug-control policy in the United States. Stanford: Hoover Institution, Sep 1995.

19 Warner K, Chaloupka FJ, Cook PJ, et al. Criteria for deter- $\overline{\bar{O}}$ mining an optimal cigarette tax: the economist's perspective. Tobacco Control 1995;4:380-6.

20 Congressional Budget Office. Federal taxation of tobacco, alcoholic beverages, and motor fuels. Washington, DC. US Government Printing Office, 1990.

21 Chapman S, Richardson J. Tobacco excise and declining consumption: The case of Papua New Guinea. Am ₹ Pubconsumption: The case of
lic Health 1990;80:537-40.

$22 \mathrm{Mao} Z \mathrm{ZZ}$. Demand for cigarette and pricing policy: a time-series $\frac{7}{O}$ analysis. [In Chinese.] Working paper, School of Public Health, West China Vicinity of Medical Sciences, Sichuan, China, 1996.

23 World Bank, China. Health finance study: health-care financing reform, 1996-2001. (Preliminary draft.) Washington, DC, Sep 1995

24 Price Waterhouse. The economic impact of the tobacco industry in the U.S. economy. New York: Price Waterhouse, 1992.

25 Warner $\mathrm{K}$, Fulton $\mathrm{G}$. The economic implementation tobacco product sales in a nontobacco state. $¥ A M A 1994$; 271:771-6.

26 Chase Econometrics. The impact of the tobacco industry in the \& United States economy in 1983. Bala Cynwyd, Pennsylvania: Chase Econometrics, 1985. 